\title{
Seletividade de Herbicidas a Genótipos de Cana-de-Açúcar ${ }^{1}$
}

\author{
Herbicide Selectivity to Sugarcane Genotypes
}

\begin{abstract}
GALON, L. ${ }^{2}$, FERREIRA, F.A. ${ }^{3}$, FERREIRA, E.A. ${ }^{4}$, SILVA, A.A. ${ }^{3}$, SILVA, A.F. ${ }^{2}$, ASPIAZÚ, I. $^{2}$, CONCENÇO, G. ${ }^{2}$, FIALHO, C.M.T. ${ }^{5}$, SANTOS, E.A. ${ }^{5}$, TIRONI, S.P. ${ }^{2}$ e BARBOSA, M.H.P. ${ }^{3}$
\end{abstract}

\begin{abstract}
RESUMO - A cultura da cana-de-açúcar, por ter desenvolvimento inicial lento até 60 dias após a emergência, apresenta pouca capacidade competitiva com as plantas daninhas. Por isso, o uso de herbicidas nesse periodo é prática comum no canavial. No entanto, há variação entre genótipos de cana-de-açúcar na tolerância a herbicidas. Os genótipos pouco tolerantes podem ser intoxicados e, em alguns casos, ocorre redução da produtividade da cana-deaçúcar. Neste trabalho, avaliou-se a tolerância de três genótipos aos herbicidas ametryn, trifloxysulfuron-sodium e à mistura comercial desses, em 0,0, 0,5, 1,0 e 3,0 vezes a dose comercial recomendada. $\mathrm{O}$ experimento foi realizado em ambiente protegido. Foi empregado o delineamento experimental inteiramente casualizado, com quatro repetições. Os tratamentos constaram dos genótipos SP80-1816, RB855113 e RB867515, combinados aos herbicidas ametryn, trifloxysulfuron-sodium e ametryn + trifloxysulfuron-sodium, nas doses de $0,0,5,1,0$ e 3,0 vezes a dose comercial recomendada pelo fabricante. A intoxicação das plantas (\%) foi avaliada aos 14, 28 e 42 dias após a aplicação dos herbicidas (DAT). As outras variáveis aferidas aos 80 dias após a brotação das gemas foram: área foliar e massa da matéria seca da parte aérea. Em geral, os genótipos SP80-1816 e RB85513 foram menos tolerantes aos herbicidas ametryn, trifloxysulfuron-sodium e à mistura formulada de ametryn + trifloxysulfuron-sodium do que o RB867515 em todas as doses. Eles apresentaram elevados indices de intoxicação aos 14, 28 e 42 dias após a aplicação dos herbicidas. Concluiu-se que o genótipo RB855113 foi o mais sensivel aos herbicidas, seguido pelo SP80-1816, sendo o RB867515 o mais tolerante.
\end{abstract}

Palavras-chave: tolerância, Saccharum spp., ametryn, trifloxysulfuron-sodium e Krismat.

\begin{abstract}
Due to a slow initial development up to 60 days after emergence, sugarcane shows little competitive capacity over weeds. Thus, the use of herbicides during this period is a common practice in the sugarcane crop. However, there is a variation between sugarcane genotypes regarding herbicide tolerance. This work evaluated the tolerance of three genotypes to the herbicides ametryn, trifloxysulfuron-sodium and their commercial formulated mixture in 0.0, 0.5, 1.0 and 3.0 times the recommended commercial dose. The experiment was conducted under protected environmental conditions. A completely randomized design was used, with four replications. The treatments were composed by genotypes SP80-1816, RB855113, RB867515 associated to herbicides ametryn, trifloxysulfuron-sodium and sodium-ametryn +trifloxysulfuron, at doses of 0, 0.5, 1.0 and 3.0 times the recommended commercial dose. Intoxication of the plants (\%) was assessed at 14, 28 and 42 days after application of the herbicides (DAT). The other variables measured at 80 days after crop emergence were leaf area and shoot dry matter. In general, the genotypes SP80-1816 and RB855113 were less tolerant to the herbicides ametryn, trifloxysulfuron- sodium and the mixture ametryn + trifloxysulfuron-sodium than the RB867515 at all tested doses. They showed high intoxication levels at 14,28 and 42 days after herbicide application. It was concluded that genotype RB8551 13 was the most sensitive to the herbicides, followed by SP80-1816, with RB867515 being the most tolerant.
\end{abstract}

Keywords: tolerance, Saccharum spp., ametryn, trifloxysulfuron-sodium and Krismat.

Recebido para publicação em 26.1.2009 e na forma revisada em 11.12.2009.

2 Engo-Agrōe, M.Sc., Doutorando no Programa de Pós-Graduação em Fitotecnia da Universidade Federal de Viçosa - DFT/UFV, Bolsista do CNPq-Brasil, 36570-000 Viçosa-MG, <galonleandro@ig.com.br>; ${ }^{3}$ Engo-Agr ${ }^{\circ}$., D.Sc., Prof. - DFT/UFV, Bolsista em

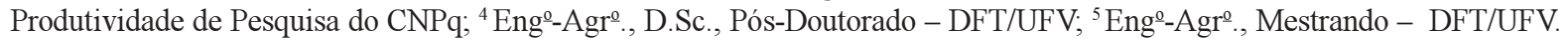




\section{INTRODUÇÃO}

A interferência exercida pelas plantas daninhas é um dos principais fatores limitantes da produtividade da cana-de-açúcar, pois essas espécies competem por água, luz, nutrientes e espaço, causando perdas significativas tanto na produtividade da cultura quanto na qualidade industrial da matéria-prima e na redução da longevidade dos canaviais. Podem também dificultar operações de colheita e transporte, sendo ainda hospedeiras de pragas e doenças (Kuva et al., 2003; Negrisoli et al., 2004; Procópio et al., 2004)

O controle das plantas daninhas nos canaviais é uma das práticas de manejo obrigatórias; o controle químico é o método mais utilizado, em razão das grandes áreas plantadas, da eficiência e do alto rendimento, aliado ao baixo custo em relação a outros métodos de controle e, também, por haver no mercado vários herbicidas registrados para essa cultura no Brasil (Procópio et al., 2004; Christoffoleti et al., 2006). Esses produtos podem, no entanto, exercer efeitos diretos e indiretos no crescimento e desenvolvimento das plantas cultivadas (Das et al., 2003; Rizzardi et al., 2003). Ressalta-se que os herbicidas aplicados em pós-emergência podem ocasionar mais intoxicação se comparados aos aplicados em pré-emergência, refletindo na escolha do produto e doses a serem aplicadas, conforme a maior ou menor tolerância do cultivar utilizado (Azania et al., 2005).

Entre os herbicidas recomendados, destacam-se o ametryn e o trifloxysulfuron-sodium, aplicados isolados ou em mistura formulada. O ametryn é um dos mais empregados no controle de folhas largas e gramíneas, sendo recomendado em pré e pós-emergência inicial (Rodrigues \& Almeida, 2005). Ele apresenta fácil absorção pelas raízes; seus sintomas de intoxicação caracterizam-se por clorose seguida de necrose, iniciando-se pelos bordos das folhas (Velini et al., 2000).

O trifloxysulfuron-sodium está registrado no Brasil para o controle de dicotiledôneas e ciperáceas em pós-emergência na cana-deaçúcar (Rodrigues \& Almeida, 2005). Os sintomas nas plantas sensiveis caracterizam-se por amarelecimento das folhas, paralisação do crescimento e morte das plantas em uma a três semanas após a aplicação. Esse herbicida, apesar de causar intoxicação diferenciada a cultivares, é recomendado para cana-deaçúcar e vem sendo amplamente utilizado em pós-emergência inicial (Procópio et al., 2004; Rodrigues \& Almeida, 2005).

Desde 2001, o herbicida ametryn é usado em mistura comercial com trifloxysulfuronsodium, formando o produto comercial Krismat $^{\circledR}$, recomendado para controle de gramíneas, dicotiledôneas e ciperáceas, sendo pouco estudado seu comportamento sobre a cana-de-açúcar (Rodrigues \& Almeida, 2005; Syngenta, 2008).

Esses herbicidas apresentam eficiência no controle de várias espécies daninhas e, em algumas situações, causam intoxicação à cultura. A magnitude da intoxicação varia em função das condições edafoclimáticas no momento da aplicação, das doses aplicadas e dos cultivares plantados. Vários pesquisadores relataram respostas diferenciadas de cultivares aos herbicidas, com consequente intoxicação da cultura, alterando características das plantas, como: altura, número de folhas, área foliar e massa da matéria seca da parte aérea das plantas de cana-de-açúcar (Procópio et al., 2004; Ferreira et al., 2005; Barela \& Christoffoleti, 2006; Azania et al., 2006).

$\mathrm{Na}$ atualidade, os programas de melhoramento genético estão liberando cultivares de cana-de-açúcar cada vez mais produtivos, com maior resistência às doenças e pragas. Entretanto, são poucos os trabalhos desenvolvidos com os cultivares mais modernos no tocante à tolerância a herbicidas (Teruel et al., 1997; Oliveira et al., 2004; Ferreira et al., 2005), incluindo avaliações sobre o crescimento e desenvolvimento da cultura.

A cana-de-açúcar tem como característica o perfilhamento abundante na fase inicial de crescimento, e são vários os fatores que influenciam essa variável, com destaque para os herbicidas. Quando o controle de plantas daninhas em pós-emergência é retardado por algum motivo, essas espécies tornam-se menos suscetiveis aos herbicidas, o que exige doses maiores que as recomendadas no rótulo dos produtos. Entretanto, o aumento dessas 
doses pode causar injúria na cultura e, ainda, contaminar o ambiente.

Desse modo, a fim de adotar o método químico para o controle de plantas daninhas na cultura da cana-de-açúcar, há necessidade de avaliar melhor a tolerância de genótipos aos herbicidas, uma vez que ela pode variar com o produto usado, o genótipo de cana plantado e as doses dos produtos, e esses fatores influenciam as características morfológicas da cultura.

Diante do exposto, objetivou-se avaliar a tolerância dos cultivares de cana-de-açúcar SP80-1816, RB855113 e RB867515 aos herbicidas ametryn, trifloxysulfuron-sodium e à sua mistura formulada comercialmente.

\section{MATERIAL E MÉTODOS}

O experimento foi instalado em ambiente protegido, no delineamento inteiramente casualizado, com quatro repetições. Cada unidade experimental constou de vaso plástico contendo 15 L de substrato (solo + fertilizantes). A adubação do solo \{Argissolo Vermelho-Amarelo (Embrapa, 2006)\} foi realizada com base nas características químicas (Tabela 1) e seguindo as recomendações técnicas para a cultura (CFSEMG, 1999). Foram plantadas duas gemas de cada cultivar de cana-de-açúcar em cada vaso. A irrigação dos vasos foi realizada por microaspersão, sempre que necessário.

Os tratamentos foram compostos pelos cultivares SP80-1816, RB855113 e RB867515, e os herbicidas, aplicados em múltiplos da dose comercial recomendada, ou seja, 0,0 , $0,5,1,0$ e 3,0 vezes a dose comercial de ametryn (2.000 $\left.\mathrm{g} \mathrm{ha}^{-1}\right)$, trifloxysulfuron-sodium $\left(22,5 \mathrm{~g} \mathrm{ha}^{-1}\right)$ e ametryn + trifloxysulfuronsodium $\left(1.463+37,0 \mathrm{~g} \mathrm{ha}^{-1}\right)$. A aplicação dos herbicidas foi realizada aos 30 dias após plantio (DAP) da cana-de-açúcar (em pós-emergência), com pulverizador costal pressurizado a $\mathrm{CO}_{2}$, munido com barra de 1,0 m - acopladas a esta duas pontas de pulverização da série TT 110.02, espaçadas de $0,5 \mathrm{~m}$ - e calibrado para aplicar o equivalente a $150 \mathrm{~L} \mathrm{ha}^{-1}$ de calda. No momento da aplicação, a temperatura era de $25{ }^{\circ} \mathrm{C}$ e a velocidade do vento de $3,4 \mathrm{~km} \mathrm{~h}^{-1}$.

O grau de intoxicação da cana-de-açúcar pelos herbicidas foi avaliado visualmente aos 14, 28 e 42 dias após a aplicação dos herbicidas (DAT), por dois avaliadores, em que a nota zero $(0 \%)$ correspondeu a nenhuma injúria e a nota cem $(100 \%)$ à morte completa das plantas. As variáveis área foliar $\left(\mathrm{cm}^{2}\right.$ por planta) e massa da matéria seca da parte aérea (g por planta) das plantas foram determinadas aos 80 dias após a brotação das gemas. A área foliar de cada genótipo foi aferida utilizando-se um determinador eletrônico de área foliar, modelo Li-cor Instruments (Modelo LI 3100), após o seccionamento rente ao solo e a separação dos colmos e das folhas. Posteriormente à determinação da área foliar, as mesmas amostras foram acondicionadas separamente em sacos de papel e acomodadas em estufa de circulação forçada de ar à temperatura de $60^{\circ} \mathrm{C}$ até atingir massa constante. Depois disso, a massa da matéria seca da parte aérea das plantas (MSPA) foi obtida em balança analítica.

Tabela 1 - Análise química do solo Argissolo Vermelho-Amarelo utilizado no experimento. Oratórios-MG, 2007

\begin{tabular}{|c|c|c|c|c|c|c|c|c|}
\hline \multirow{2}{*}{\multicolumn{2}{|c|}{ Camada amostrada }} & $\mathrm{pH}$ & $\mathrm{P}$ & $\mathrm{K}^{+}$ & $\mathrm{H}+\mathrm{Al}$ & $\mathrm{Al}^{3+}$ & $\mathrm{Ca}^{2+}$ & $\mathrm{Mg}^{2+}$ \\
\hline & & $\left(\mathrm{H}_{2} \mathrm{O}\right)$ & \multicolumn{3}{|c|}{$\left(\mathrm{mg} \mathrm{dm}^{-3}\right)$} & \multicolumn{3}{|c|}{$\left(\mathrm{cmol}_{\mathrm{c}} \mathrm{dm}^{-3}\right)$} \\
\hline \multicolumn{2}{|c|}{$0-10 \mathrm{~cm}$} & 5,1 & 4,5 & 33 & 2,15 & 0,2 & 1,5 & 0,7 \\
\hline $\mathrm{SB}$ & $\overline{\mathrm{CTC}(\mathrm{t})}$ & $\mathrm{CTC}(\mathrm{T})$ & $\overline{\mathrm{v}}$ & $\bar{m}$ & $\mathrm{MO}$ & Argila & Areia & Silte \\
\hline \multicolumn{3}{|c|}{$\left(\mathrm{cmol}_{\mathrm{c}} \mathrm{dm}^{-3}\right)$} & \multicolumn{2}{|c|}{$(\%)$} & \multicolumn{2}{|c|}{$\left(\right.$ dag kg $\left.{ }^{-1}\right)$} & \multicolumn{2}{|c|}{$(\%)$} \\
\hline 2,28 & 2,48 & 2,48 & 51 & 8,0 & 0,9 & 39 & 43 & 18 \\
\hline
\end{tabular}

1/ Análise realizada no Laboratório de Análise de Solos Viçosa Ltda. pH: em água, relação 1:2,5. P-K: extrator Mehlich 1. Ca-Mg e Al: extrator $\mathrm{KCl}-1 \mathrm{~mol} \mathrm{~L}^{-1} \cdot \mathrm{H}+\mathrm{Al}$ : extrator acetato de cálcio $0,5 \mathrm{~mol} \mathrm{~L}^{-1}-\mathrm{pH} 7,0$. SB: soma de bases trocáveis. CTC (t): capacidade de troca catiônica efetiva. CTC (T): capacidade de troca catiônica a pH 7,0. v: saturação de bases. m: saturação de alumínio. MO: matéria orgânica $=$ C.org x 1,724 - Walkley-Black. 
Os dados foram submetidos ao teste de homocedasticidade e, em seguida, à análise de variância. Posteriormente, análises de regressões lineares e não lineres foram realizadas para avaliar os efeitos das doses dos herbicidas, utilizando-se as médias de cada tratamento. A escolha dos modelos baseou-se na significância estatística (teste F), no ajuste do coeficiente de determinação $\left(R^{2}\right)$ e no significado biológico do modelo, conforme o proposto por Adati et al. (2006), com pequenas adaptações. Realizou-se ainda o teste de Tukey para avaliar a influência de ametryn, trifloxysulfuron-sodium e da mistura de ametryn + trifloxisulfuron-sodium sobre os genótipos SP80-1816, RB855113 e RB867515. Adotou-se probabilidade de erro de $5 \%$ para todas as análises estatísticas efetuadas.

\section{RESULTADOS E DISCUSSÃO}

Ocorreu interação entre genótipos, herbicidas e doses para todas as variáveis estudadas. Constatou-se acréscimo da intoxicação com o aumento das doses de ametryn aos 14 DAT em todos os genótipos avaliados, sendo a intoxicação máxima observada com três vezes a dose recomendada. Com o herbicida trifloxysulfuron-sodium e sua mistura com ametryn foi observada estabilização da intoxicação nos genótipos a partir da meia dose aplicada (Figura 1).

Aos 28 DAT, os genótipos RB855113 e SP80-1816 apresentaram aumento dos niveis de intoxicação para o ametryn com o aumento das doses. A intoxicação máxima, quando se aplicou três vezes a dose recomendada para a cultura, foi de aproximadamente $75 \%$ (Figura 2). O RB867515 apresentou menores níveis de intoxicação ocasionados pelo ametryn mesmo nas doses mais elevadas, em torno de $20 \%$. O uso do trifloxysulfuron-sodium estabilizou os sintomas de intoxicação nos três genótipos a partir da metade da dose recomendada; no entanto, o SP80-1816 apresentou niveis de intoxicação um pouco mais pronunciados que o dos genótipos RB855113 e RB867515. O acréscimo das doses da mistura comercial de ametryn + trifloxysulfuron-sodium aumentou a intoxicação do RB855113, chegando a cerca de 15 e $25 \%$ com a dose e com o triplo da dose recomendada, respectivamente. Nos demais genótipos o acréscimo nos níveis de intoxicação foi menor.

Aos 42 DAT, o ametryn manteve os índices elevados de intoxicação (aproximadamente $65 \%$ ) ao cultivar SP80-1816 na maior dose testada; a injúria foi de $10 \%$ com o uso da dose de rótulo (Figura 3). Menor grau de intoxicação foi observado sobre o RB855113 nas doses recomendadas e no triplo destas, em torno de 15 e 25\%, respectivamente. Para o RB867515, a evolução dos niveis de intoxicação foi baixa, com valores próximos a $5 \%$ em todas as doses avaliadas. Esses resultados concordam com os observados por Ferreira et al. (2005). $\mathrm{O}$ trifloxysulfuron-sodium provocou elevada intoxicação nos genótipos SP80-1816 e RB855113 ao se usar o triplo da dose, porém, na dose recomendada, o nível de dano a esses cultivares não ultrapassou $20 \%$. Baixos índices de intoxicação foram verificados para a mistura de ametryn + trifloxysulfuron-sodium mesmo nas doses mais altas.

Para o herbicida ametryn, aos 14, 28 e 42 DAT, o cultivar RB867515 apresentou menores indices de intoxicação em todas as doses testadas. O trifloxysulfuron-sodium, nas duas primeiras avaliações, causou baixos danos à cultura nos três cultivares, mesmo na maior dose testada, porém na última avaliação somente o genótipo RB867513 mostrou elevado indice de intoxicação. Esse fato pode ser explicado em razão de o trifloxysulfuronsodium ser inibidor da enzima ALS, e os herbicidas com esse mecanismo de ação normalmente têm ação mais lenta, chegando a semanas para evidenciar efeitos de injúrias às plantas (Rodrigues \& Almeida, 2005). Por fim, a mistura de ametryn + trifloxysulfuronsodium, em todas as épocas avaliadas e genótipos, independentemente de dose, ocasionou baixos indices de intoxicação (Figuras 1, 2 e 3).

Os resultados demonstram, para os efeitos de herbicida $x$ genótipos aos 14 DAT, que a aplicação dos três herbicidas não ocasionou efeito sobre nenhum dos cultivares estudados, exceto sobre o RB867515 para o herbicida trifloxysulfuron-sodium na metade da dose recomendada (Tabela 2). Não houve diferença entre os cultivares ao se aplicar a dose de rótulo na presença do ametryn e de ametryn + trifloxysulfuron-sodium, considerando que os sintomas de intoxicação variaram de 8,0 a 

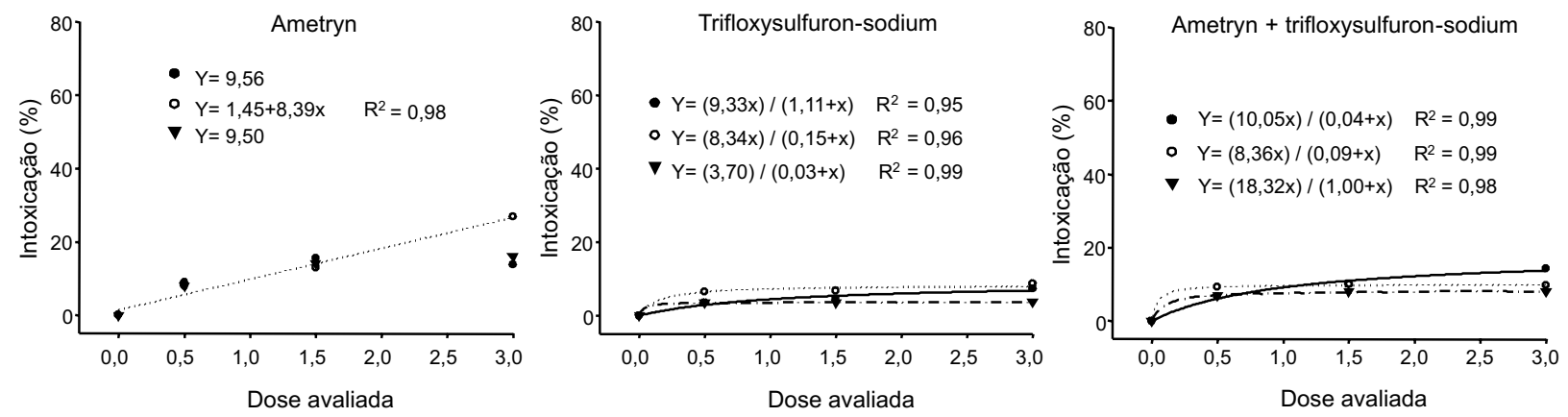

Figura 1 - Intoxicação (\%) de plantas de cana-de-açúcar em função de herbicidas e doses múltiplas da comercial (g ha-1), avaliada aos 14 dias após a aplicação dos herbicidas. UFV-Oratórios-MG, 2007. O SP80-1816 - • RB855113 - $\nabla$ RB867515.
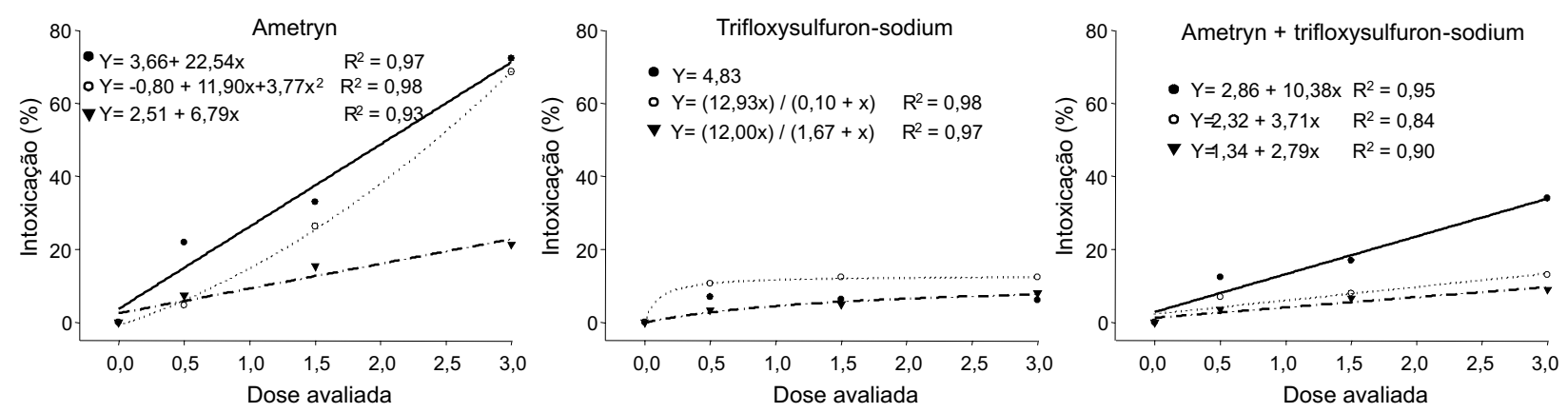

Figura 2 - Intoxicação (\%) de plantas de cana-de-açúcar em função de herbicidas e doses múltiplas da comercial ( $\left.\mathrm{g}^{\text {ha }}{ }^{-1}\right)$, avaliada aos 28 dias após a aplicação dos herbicidas. UFV-Oratórios-MG, 2007. O SP80-1816 - • RB855113 - $\nabla$ RB867515
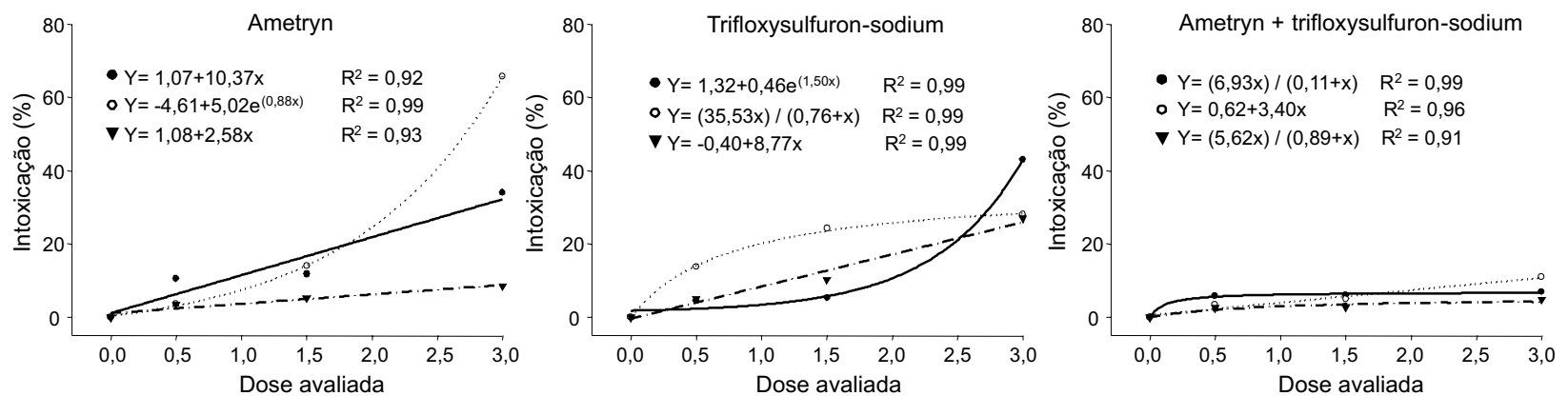

Figura 3 - Intoxicação (\%) de plantas de cana-de-açúcar em função de herbicidas e doses múltiplas da comercial (g ha-1), avaliada aos 42 dias após a aplicação dos herbicidas. UFV-Oratórios-MG, 2007. O SP80-1816 - • RB855113 - $\nabla$ RB867515.

$15,5 \%$ para os respectivos herbicidas nos genótipos testados. Menores níveis de intoxicação foram observados para o trifloxysulfuronsodium, apresentando diferenças tanto entre os herbicidas como entre os cultivares, porém com niveis de intoxicação mais baixos que os dos demais herbicidas; os genótipos RB855113 e RB867515 apresentaram os menores indices de intoxicação em relação ao SP80-1816. O maior grau de injúria foi observado quando se aplicou o triplo da dose recomendada, destacando-se que o cultivar SP80-1816 foi o mais afetado pelo ametryn nessa ocasião, seguido do RB867515 e RB855113, com valores 
Tabela 2 - Intoxicação da cana-de-açúcar em função de herbicidas, doses múltiplas da comercial (g ha-1) e de genótipos, avaliada aos 14, 28 e 42 dias após a aplicação dos herbicidas (DAT). DFT/UFV, Oratórios-MG

\begin{tabular}{|c|c|c|c|c|c|c|c|c|c|c|}
\hline \multirow{3}{*}{$\begin{array}{c}\text { Dose } \\
\text { avaliada }\end{array}$} & \multirow{3}{*}{ Herbicida } & \multicolumn{9}{|c|}{ Intoxicação (\%) } \\
\hline & & \multicolumn{3}{|c|}{14 DAT } & \multicolumn{3}{|c|}{$28 \mathrm{DAT}$} & \multicolumn{3}{|c|}{42 DAT } \\
\hline & & SP80-1816 & RB855113 & RB867515 & SP80-1816 & RB855113 & RB867515 & SP80-1816 & RB855113 & RB867515 \\
\hline \multirow{3}{*}{0} & $\mathrm{HA}^{\frac{1 /}{}}$ & $0,0 \mathrm{aA}^{2 /}$ & $0,0 \mathrm{aA}$ & $0,0 \mathrm{aA}$ & $0,0 \mathrm{aA}$ & $0,0 \mathrm{aA}$ & $0,0 \mathrm{aA}$ & $0,0 \mathrm{aA}$ & $0,0 \mathrm{aA}$ & $0,0 \mathrm{aA}$ \\
\hline & $\mathrm{HB}$ & $0,0 \mathrm{aA}$ & $0,0 \mathrm{aA}$ & $0,0 \mathrm{aA}$ & $0,0 \mathrm{aA}$ & $0,0 \mathrm{aA}$ & $0,0 \mathrm{aA}$ & $0,0 \mathrm{aA}$ & $0,0 \mathrm{aA}$ & $0,0 \mathrm{aA}$ \\
\hline & $\mathrm{HC}$ & $0,0 \mathrm{aA}$ & $0,0 \mathrm{aA}$ & $0,0 \mathrm{aA}$ & $0,0 \mathrm{aA}$ & $0,0 \mathrm{aA}$ & $0,0 \mathrm{aA}$ & $0,0 \mathrm{aA}$ & $0,0 \mathrm{aA}$ & $0,0 \mathrm{aA}$ \\
\hline \multirow{3}{*}{0,5} & HA & $8,0 \mathrm{aA}$ & $9,0 \mathrm{aA}$ & $8,0 \mathrm{aA}$ & $4,7 \mathrm{aB}$ & $22,0 \mathrm{aA}$ & $7,3 \mathrm{aB}$ & $3,8 \mathrm{bA}$ & $10,5 \mathrm{aA}$ & $3,5 \mathrm{aA}$ \\
\hline & $\mathrm{HB}$ & $6,8 \mathrm{aA}$ & $7,3 \mathrm{aA}$ & $3,8 \mathrm{bB}$ & $10,7 \mathrm{aA}$ & $7,0 \mathrm{bAB}$ & $3,3 \mathrm{aB}$ & $13,8 \mathrm{aA}$ & $4,5 \mathrm{aB}$ & $5,0 \mathrm{aB}$ \\
\hline & $\mathrm{HC}$ & $9,3 \mathrm{aA}$ & $6,8 \mathrm{aA}$ & $7,0 \mathrm{aA}$ & $8,0 \mathrm{aAB}$ & $12,3 \mathrm{bA}$ & $3,7 \mathrm{aB}$ & $3,5 \mathrm{bA}$ & $5,8 \mathrm{aA}$ & $2,5 \mathrm{aA}$ \\
\hline \multirow{3}{*}{1,0} & HA & $13,0 \mathrm{aA}$ & $15,5 \mathrm{aA}$ & $14,0 \mathrm{aA}$ & $26,3 \mathrm{aA}$ & $33,0 \mathrm{aA}$ & $15,3 \mathrm{aB}$ & $14,0 \mathrm{bA}$ & $11,8 \mathrm{aAB}$ & $5,3 \mathrm{bB}$ \\
\hline & HB & $6,5 \mathrm{cA}$ & $3,5 \mathrm{cB}$ & $3,5 \mathrm{cB}$ & $12,3 \mathrm{bA}$ & $6,3 \mathrm{cA}$ & $8,0 \mathrm{bA}$ & $28,0 \mathrm{aA}$ & $5,3 \mathrm{aB}$ & $27,0 \mathrm{aA}$ \\
\hline & $\mathrm{HC}$ & $10,0 \mathrm{bA}$ & $10,0 \mathrm{bA}$ & $8,0 \mathrm{bA}$ & $7,0 \mathrm{bB}$ & $17,0 \mathrm{bA}$ & $6,7 \mathrm{bB}$ & $11,0 \mathrm{bA}$ & $6,0 \mathrm{aA}$ & $2,8 \mathrm{bA}$ \\
\hline \multirow{3}{*}{3,0} & HA & $26,8 \mathrm{aA}$ & $13,8 \mathrm{aB}$ & $16,0 \mathrm{aB}$ & $68,7 \mathrm{aA}$ & $72,3 \mathrm{aA}$ & $21,3 \mathrm{aB}$ & $65,8 \mathrm{aA}$ & $34,0 \mathrm{bB}$ & $8,5 \mathrm{aC}$ \\
\hline & $\mathrm{HB}$ & $8,8 \mathrm{bA}$ & $4,5 \mathrm{bB}$ & $3,5 \mathrm{cB}$ & $12,3 \mathrm{bA}$ & $6,0 \mathrm{cAB}$ & $5,0 \mathrm{bB}$ & $24,3 \mathrm{bB}$ & $43,0 \mathrm{aA}$ & $10,3 \mathrm{aC}$ \\
\hline & $\mathrm{HC}$ & $9,8 \mathrm{bB}$ & $14,3 \mathrm{aA}$ & $8,0 \mathrm{bB}$ & $13,0 \mathrm{bB}$ & $34,0 \mathrm{bA}$ & $9,0 \mathrm{bB}$ & $5,0 \mathrm{cA}$ & $7,0 \mathrm{cA}$ & $4,8 \mathrm{aA}$ \\
\hline \multicolumn{2}{|c|}{ Média Geral } & \multicolumn{3}{|c|}{7,08} & \multicolumn{3}{|c|}{12,67} & \multicolumn{3}{|c|}{10,17} \\
\hline \multicolumn{2}{|c|}{ CV (\%) } & \multicolumn{3}{|c|}{24,21} & \multicolumn{3}{|c|}{32,32} & \multicolumn{3}{|c|}{49,91} \\
\hline
\end{tabular}

${ }^{1 /} \mathrm{HA}$ : ametryn $\left(2.000 \mathrm{~g} \mathrm{ha}^{-1}\right)$; HB: trifloxysulfuron-sodium $\left(22,5 \mathrm{~g} \mathrm{ha}^{-1}\right)$; HC: ametryn + trifloxysulfuron-sodium $\left(1.673+37,0 \mathrm{~g} \mathrm{ha}^{-1}\right)$ 2 Médias seguidas por mesmas letras minúsculas, na coluna, dentro de cada genótipo entre os herbicidas e seguidas por mesmas letras maiúsculas, na linha, entre os genótipos não diferem entre si pelo teste de Tukey $(\mathrm{p} \leq 0,05)$.

aproximados de 27, 16 e 13,75\% de intoxicação, respectivamente. O trifloxysulfuron-sodium e a mistura mostraram menores niveis de injúrias, mas com diferenças entre os cultivares, excetuando-se o RB855113, que chegou a um nível de intoxicação de aproximadamente $14,25 \%$.

Observou-se aos 28 DAT que não houve diferenças entre todos os herbicidas aplicados em meia dose, exceto para o cultivar RB855113, que foi o mais sensivel ao trifloxysulfuronsodium e ametryn + trifloxysulfuron-sodium (Tabela 2). Houve diferenciação entre os cultivares testados em cada herbicida avaliado: o RB855113 foi mais sensivel aos três herbicidas, e o SP80-1816 também apresentou elevadas injúrias causadas pelo trifloxysulfuron-sodium e pela mistura de ametryn+trifloxysulfuron-sodium. Levando em conta a dose recomendada e a aplicação de três vezes a dose, comparando-se os herbicidas e os genótipos, constatou-se que o ametryn apresentou as maiores intoxicações que os demais herbicidas nos três genótipos avaliados, e o SP80-1816 e o RB855113 foram os menos tolerantes aos três herbicidas testados. Na dose recomendada, o ametryn provocou incremento nos valores de intoxicação para os genótipos
SP80-1816, RB855113 e RB867515 (valores aproximados de 26,33 e 15\%, respectivamente). $\mathrm{O}$ efeito do trifloxysulfuron-sodium foi semelhante entre os cultivares, com niveis baixos de intoxicação. Com a mistura, o RB855113 foi mais sensivel, chegando a aproximadamente $17 \%$ de intoxicação, diferindo dos demais genótipos. Com o triplo da dose recomendada, o ametryn mostrou-se mais tóxico: os niveis atingiram aproximadamente 69, 72 e 15\% para os genótipos SP80-1816, RB855113 e RB867515, respectivamente. Não houve variação considerável entre os genótipos para o trifloxysulfuron-sodium, causando baixos niveis de intoxicação, comparando a metade da dose e a dose recomendada.

Aos 42 DAT os niveis de intoxicação foram mais baixos (Tabela 2), denotando a recuperação da plantas tratadas com os herbicidas. Na metade da dose recomendada do ametryn, os valores de intoxicação atingiram o índice máximo de 10,5\% para o RB855113. Usando o trifloxysulfuron-sodium, a intoxicação foi de $14 \%$ para o genótipo SP80-1816. A mistura proporcionou baixos valores de intoxicação, sem diferença entre os cultivares. Na dose recomendada, constatou-se elevada intoxicação pelo ametryn para os cultivares SP80-1816 
e RB855113 (14 e 11,75\%, respectivamente) e pelo trifloxysulfuron-sodium para o SP80-1816 e RB867515, com índices de 28 e $27 \%$, respectivamente, diferenciando dos demais genótipos tratados. Para o triplo da dose, os valores de injúria permaneceram elevados para os cultivares SP80-1816 e RB855113 (65,75 e 43,00\%) com a aplicação de ametryn e trifloxysulfuronsodium, respectivamente. A mistura de ametryn+trifloxysulfuron-sodium foi a que apresentou os menores valores de intoxicação em relação aos demais, e todos os genótipos não mostraram diferenças entre si ao se aplicar a maior dose dessa mistura.

Alguns pesquisadores também observaram intoxicação das plantas de cana-de-açúcar ao usarem doses crescentes de herbicidas, com diferenciação entre os genótipos e herbicidas aplicados. Ferreira et al. (2005), ao estudarem a mistura de ametryn + trifloxysulfuronsodium em 11 cultivares e quatro clones de cana-de-açúcar, observaram que o cultivar RB855113 e o clone RB957689 foram mais sensiveis à mistura de ametryn + trifloxysulfuronsodium, apresentando, respectivamente, indices de intoxicação média de 13,75 e 15\% aos 13 DAT, enquanto os demais cultivares mostraram intoxicação média inferior a 10\%. Com o incremento da dose com essa mistura formulada, esses autores verificaram ainda aumento acentuado dos sintomas para o RB855113, o qual se apresentou com maior sensibilidade aos 13 DAT. O trifloxysulfuronsodium aplicado isoladamente ou em mistura com o ametryn não causou intoxicação no cultivar RB72454 em campo (Freitas et al., 2004) na dose recomendada. Azania et al. (2001), ao trabalharem com os herbicidas imazapyr e tebuthiuron aplicados no cultivar RB835089, constataram leve intoxicação na fase inicial do desenvolvimento e total recuperação da cultura aos 100 DAT, sem prejuízo para produtividade e qualidade da matériaprima. Tolerância diferenciada de genótipos de cana-de-açúcar foi também verificada por Velini et al. (2000). Esses autores pesquisaram 10 cultivares submetidos à mistura de oxyfluorfen + ametryn e constataram que o cultivar SP80-1842 apresentou alta sensibilidade a esses herbicidas, sendo observado indice de intoxicação superior a 44\%.

De acordo com Velini et al. (1993), o índice de intoxicação considerado tolerado pela cultura da cana-de-açúcar sem que ocorram danos nos aspectos produtivos é de $27 \%$. O ametryn, quando aplicado sobre os genótipos SP80-1816 e RB855113, não pode ser recomendado além da dose comercial, por provocar injúrias superiores à tolerada e influenciar diretamente a produtividade da cultura. O mesmo não ocorreu com o trifloxysulfuron-sodium e a mistura de ametryn+trifloxysulfuron-sodium quando aplicados sobre todos os genótipos. Apenas para o genótipo RB855113, ao aplicar três vezes a dose comercial, tanto para o trifloxysulfuronsodium aplicado isoladamente, aos 28 DAT, como para sua mistura, aos 42 DAT, as injúrias foram superiores à tolerada pela cultura.

A área foliar das plantas foi menor em função do aumento das doses dos herbicidas ametryn e trifloxysulfuron-sodium quando aplicados isoladamente ou em mistura formulada (Figura 4). O ametryn foi o que provocou maiores efeitos negativos sobre essa variável, com resultados semelhantes entre os três
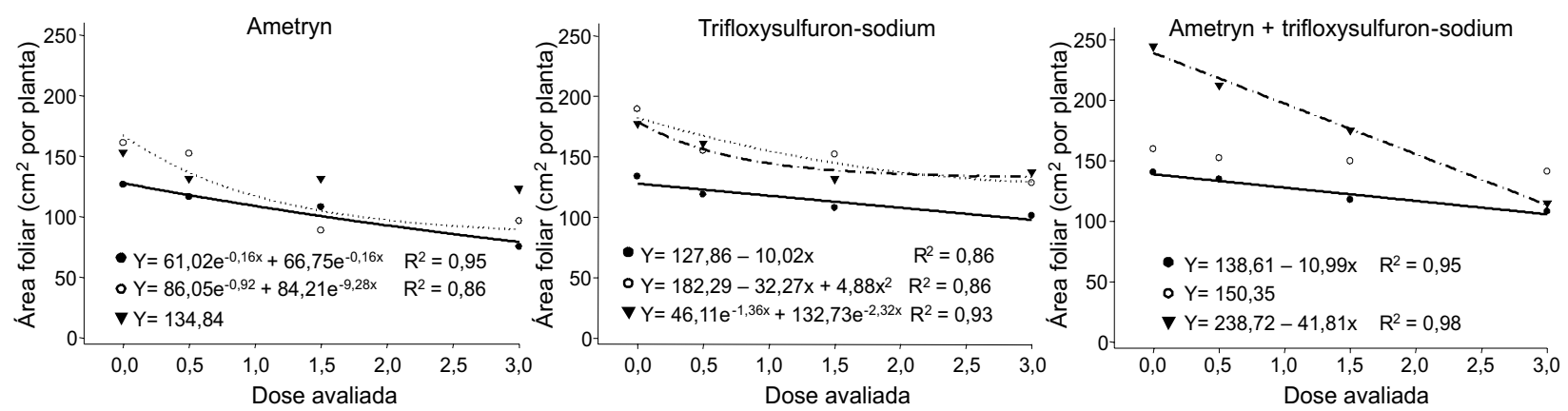

Figura 4 - Área foliar ( $\mathrm{cm}^{2}$ por planta) de genótipos de cana-de-açúcar em função de herbicidas e doses múltiplas da comercial ( $\mathrm{g}$ ha-1 $)$, avaliada aos 80 dias após a brotação das gemas. UFV-Oratórios-MG, 2007. O SP80-1816 - • RB855113 - $\nabla$ RB867515.

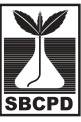


cultivares. Observou-se, ao aplicar três vezes a dose recomendada de ametryn, que o crescimento de área foliar nos cultivares foi em torno de $50 \%$ menor que o da testemunha sem aplicação do herbicida $\left(0 \mathrm{~g} \mathrm{ha}^{-1}\right)$. Trifloxysulfuron-sodium, por sua vez, ocasionou menor efeito negativo sobre os cultivares que o ametryn. É possivel inferir que o cultivar RB855113 foi mais sensivel que os demais ao trifloxysulfuron-sodium, com queda mais acentuada na área foliar quando se aumentou a dose do herbicida. A mistura de ametryn + trifloxysulfuron-sodium causou menor comprometimento da variável em estudo ao genótipo RB867515 que os demais herbicidas; contudo, esse genótipo também reduziu a área foliar em relação aos demais, devido ao aumento na dose da mistura. Ao pesquisarem herbicidas de ação localizada aplicados sobre a cana-deaçúcar, Velini et al. (1993) constataram que a cultura pode tolerar até $27 \%$ do comprometimento de sua área foliar sem que haja redução da produtividade. No entanto, para herbicidas sistêmicos esses valores podem ser diferentes, dependendo do processo fisiológico afetado pelo produto. Ferreira et al. (2005) relataram que a mistura de ametryn + trifloxysulfuron-sodium ocasionou redução de $80 \%$ da área foliar do genótipo de cana-deaçúcar RB855113 ao aplicar seis vezes a dose comercial do herbicida, comparada com a testemunha sem aplicação, enquanto no genótipo RB867515 a diminuição da área foliar foi de somente $20 \%$. Desse modo, fica claro que a intoxicação varia entre os genótipos cultivados e com a dose dos herbicidas utilizados.

Quanto à variável área foliar, observou-se diferença entre os genótipos na ausência da aplicação de herbicidas: o SP80-1816 foi o mais e o RB855113 o menos produtivo, e o RB867515 apresentou resultado intermediário (Tabela 3). Na comparação dos genótipos sob ação do ametryn e do trifloxysulfuron-sodium, observou-se maior área foliar no SP80-1816 e RB867515; este último também se destacou com a mistura de ametryn + trifloxysulfuronsodium na meia dose dos herbicidas. O genótipo RB855113 apresentou-se como o menos tolerante a todos os herbicidas testados. A área foliar dos genótipos SP80-1816 e RB855113 não apresentou diferença sob ação dos três herbicidas. O RB867515 foi influenciado negativamente pela ação do ametryn e trifloxysulfuron-sodium. De modo geral, para a dose e o triplo da dose recomendada, observou-se que os genótipos RB867515 e SP80-1816 foram os que menos influência negativa sofreram pela ação dos herbicidas, e o RB855113 foi o mais afetado com menor área foliar. Ao comparar os três herbicidas influenciando cada cultivar, observou-se que o trifloxysulfuron-sodium ocasionou maior área foliar ao SP80-1816. Os três genótipos apresentaram maior e menor área foliar quando se aplicou a mistura de ametryn+ trifloxysulfuron-sodium e o ametryn, respectivamente, no triplo da dose recomendada.

Ressalta-se que a maior área foliar implica maior captura de luz pelas plantas ou dossel e, desse modo, maior será a capacidade da planta de fotossintetizar e, consequentemente, maior a produtividade (Inman-Bamber, 1994). As diferenças entre genótipos de cana-deaçúcar foram evidentes sob efeito de ametryn +trifloxysulfuron-sodium em seis doses comerciais no desenvolvimento da área foliar

Tabela 3 - Área foliar (AF) de plantas de cana-de-açúcar em função de herbicidas, doses múltiplas da comercial e de genótipos, avaliada aos 80 dias após brotação das gemas. DFT/UFV, Oratórios-MG

\begin{tabular}{|c|c|c|c|c|}
\hline \multirow{2}{*}{$\begin{array}{c}\text { Dose } \\
\text { avaliada }\end{array}$} & \multirow{2}{*}{ Herbicida } & \multicolumn{3}{|c|}{$\mathrm{AF}\left(\mathrm{cm}^{2}\right.$ por planta $)$} \\
\hline & & SP80-1816 & RB855113 & RB867515 \\
\hline \multirow{3}{*}{0} & $\mathrm{HA}^{\frac{1}{\prime}}$ & $151,86 \mathrm{aA}^{\underline{2}}$ & $107,81 \mathrm{aB}$ & $131,38 \mathrm{aAB}$ \\
\hline & HB & 151,86 aA & $107,81 \mathrm{aB}$ & $131,38 \mathrm{aAB}$ \\
\hline & $\mathrm{HC}$ & 151,86 aA & $107,81 \mathrm{aB}$ & 131,38 aAB \\
\hline \multirow{3}{*}{0,5} & HA & 161,26 aA & $126,22 \mathrm{aB}$ & $153,30 \mathrm{bAB}$ \\
\hline & $\mathrm{HB}$ & 154,80 aA & $118,72 \mathrm{aB}$ & 177,19 bA \\
\hline & $\mathrm{HC}$ & $149,32 \mathrm{aB}$ & $134,46 \mathrm{aB}$ & 189,12 aA \\
\hline \multirow{3}{*}{1,0} & HA & $88,51 \mathrm{cB}$ & $116,32 \mathrm{aAB}$ & $123,05 \mathrm{cA}$ \\
\hline & HB & 189,29 aA & $133,81 \mathrm{aB}$ & $160,91 \mathrm{bAB}$ \\
\hline & $\mathrm{HC}$ & $140,90 \mathrm{bB}$ & $139,90 \mathrm{aB}$ & 244,13 aA \\
\hline \multirow{3}{*}{3,0} & HA & 96,49 bB & $75,07 \mathrm{bB}$ & $131,63 \mathrm{bA}$ \\
\hline & $\mathrm{HB}$ & 127,99 abAB & $100,99 \mathrm{abB}$ & 137,58 bA \\
\hline & $\mathrm{HC}$ & 159,32 aA & $117,30 \mathrm{aB}$ & 174,67 aA \\
\hline \multicolumn{2}{|c|}{ Média Geral } & \multicolumn{3}{|c|}{138,94} \\
\hline \multicolumn{2}{|l|}{ CV (\%) } & \multicolumn{3}{|c|}{14,77} \\
\hline
\end{tabular}

1/ HA: ametryn (2.000 $\left.\mathrm{g} \mathrm{ha}^{-1}\right)$; HB: trifloxysulfuron-sodium $\left(22,5 \mathrm{~g} \mathrm{ha}^{-1}\right)$; HC: ametryn + trifloxysulfuron-sodium $(1.673+$ $\left.37,0 \mathrm{~g} \mathrm{ha}^{-1}\right) .{ }^{2 /}$ Médias seguidas por mesmas letras minúsculas, na coluna, dentro de cada genótipo entre os herbicidas e seguidas por mesmas letras maiúsculas, na linha, entre os genótipos não diferem entre si pelo teste de Tukey $(\mathrm{p} \leq 0,05)$ 
(Ferreira et al., 2005). Também Velini et al. (2000), ao estudarem o oxyfluorfen e ametryn isolados e em mistura formulada, observaram diferentes niveis de intoxicação na área foliar de dez genótipos de cana-de-açúcar tanto em aplicações em pré como em pós-emergência.

A variável massa da matéria seca da parte aérea (MSPA) dos genótipos decresceu com o aumento nas doses aplicadas dos três herbicidas (Figura 5). O cultivar SP80-1816 foi um dos mais sensíveis ao ametryn, com MSPA ao redor de $12 \mathrm{~g}$ por planta na maior dose recomendada, contra $37 \mathrm{~g}$ por planta na testemunha sem herbicida. O trifloxysulfuron-sodium ocasionou menor redução na MSPA das plantas quando se aumentou a dose do que o ametryn, com maior semelhança de comportamento entre cultivares. Na maior dose do de trifloxysulfuron-sodium, a produção MSPA para os três cultivares foi $37 \%$ menor, em relação à testemunha. O comportamento dos cultivares de cana-de-açúcar para a MSPA em função de doses de ametryn + trifloxysulfuronsodium foi semelhante ao observado para a aplicação isoladamente dos herbicidas; na dose mais elevada, o valor foi em torno de $73 \%$ menor que o observado na testemunha sem aplicação. Segundo Ferreira et al. (2005), com o aumento nas doses de ametryn + trifloxysulfuron-sodium aplicados sobre a canade-açúcar, a produção da massa da matéria seca da parte aérea de 11 genótipos de canade-açúcar foi menor e diferente entre os materiais testados.

À semelhança da área foliar, a MSPA também apresentou diferenças entre os genótipos, com destaque para SP80-1816 e RB855113. O genótipo RB867515 foi o que menos produziu (Tabela 4). O SP80-1816 apresentou mais MSPA sob ação do ametryn; o RB855113, sob ação do trifloxysulfuron-sodium; e o RB867515, com trifloxysulfuron-sodium e também o ametryn + trifloxysulfuron-sodium, na metade da dose comercial recomendada.

O SP80-1816 foi mais tolerante aos herbicidas ametryn e à mistura (Tabela 4). Para o ametryn + trifloxysulfuron-sodium, também o RB867515 produziu mais MSPA, enquanto o RB855113 não foi influenciado pelos herbicidas ao se aplicar meia dose. O genótipo RB867515 foi o que maior MSPA apresentou, comparado com os demais genótipos, na ação individual dos herbicidas ao se usar uma vez a dose recomendada, e o SP80-1816 e o RB855113 apresentaram produção similar de MSPA para os herbicidas testados. O genótipo RB867515 foi tolerante aos herbicidas aplicados, enquanto o SP80-1816 e o RB855113 apresentaram maior produção de MSPA quando se aspergiu o trifloxysulfuron-sodium e a mistura de ametryn + trifloxysulfuron-sodium na dose recomendada. Não houve diferença entre os genótipos para a MSPA sob ação dos herbicidas na maior dose testada. Entretanto, observou-se maior produção de MSPA quando se compararam os três genótipos sob ação do trifloxysulfuron-sodium e da mistura formulada. O ametryn foi o mais tóxico para SP801816, RB855113 e RB867515, com redução da MSPA para a maior dose.

De maneira geral, observa-se que a intoxicação ocasionada pelos herbicidas aos
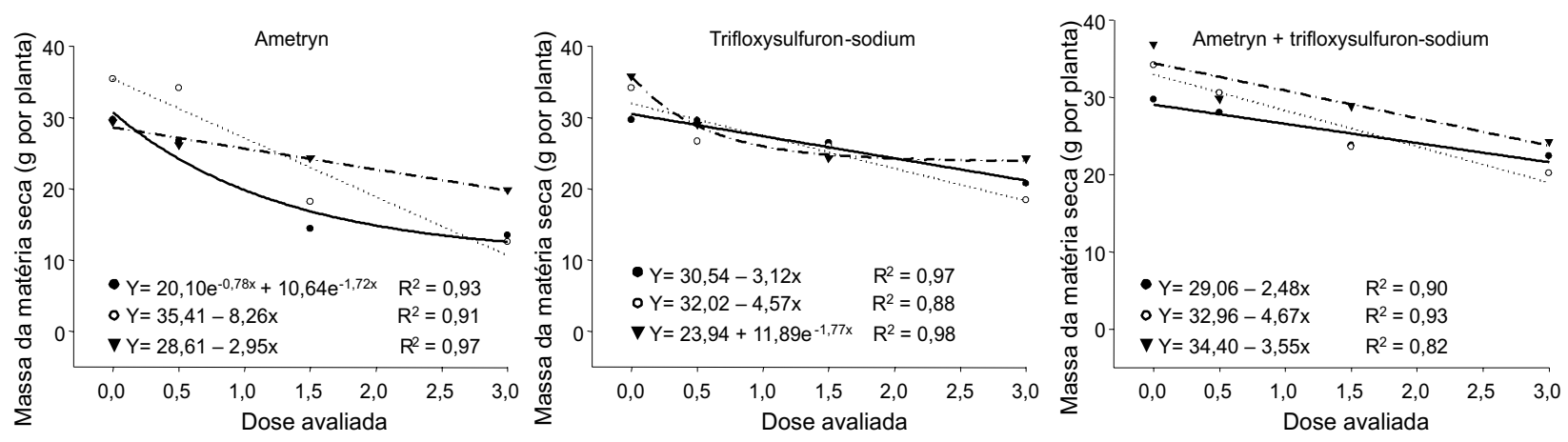

Figura 5 - Massa da matéria seca da parte aérea (g por planta) de plantas de cana-de-açúcar em função de herbicidas e doses múltiplas da comercial ( $\mathrm{g} \mathrm{ha}^{-1}$ ), avaliada aos 80 dias após a brotação das gemas. UFV-Oratórios-MG, 2007. o SP80-1816 - • RB855113 - $\nabla$ RB867515

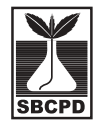


Tabela 4 - Massa da matéria seca da parte aérea (MSPA) de cana-de-açúcar em função de herbicidas, dose múltiplas da comercial e de genótipos, avaliada aos 80 dias após a brotação das gemas. DFT/UFV, Oratórios-MG

\begin{tabular}{|c|c|c|c|c|}
\hline \multirow{2}{*}{$\begin{array}{c}\text { Dose } \\
\text { avaliada }\end{array}$} & \multirow{2}{*}{ Herbicida } & \multicolumn{3}{|c|}{ MSPA (g por planta) } \\
\hline & & SP80-1816 & RB855113 & RB867515 \\
\hline \multirow{3}{*}{0} & $\mathrm{HA}^{\frac{1}{}}$ & $34,18 \mathrm{aA}^{2 /}$ & $29,69 \mathrm{aAB}$ & $24,31 \mathrm{aB}$ \\
\hline & $\mathrm{HB}$ & 34,18 aA & 29,69 aAB & $24,31 \mathrm{aB}$ \\
\hline & $\mathrm{HC}$ & 34,18 aA & $29,69 \mathrm{aAB}$ & $24,31 \mathrm{aB}$ \\
\hline \multirow{3}{*}{0,5} & $\mathrm{HA}$ & 35,41 aA & $26,75 \mathrm{aB}$ & $26,19 \mathrm{bB}$ \\
\hline & $\mathrm{HB}$ & $18,40 \mathrm{bB}$ & 29,61 aA & 29,06 bA \\
\hline & $\mathrm{HC}$ & $30,58 \mathrm{aB}$ & $22,37 \mathrm{aC}$ & 42,35 aA \\
\hline \multirow{3}{*}{1,0} & HA & $18,19 \mathrm{bB}$ & $13,51 \mathrm{bB}$ & 29,34 aA \\
\hline & $\mathrm{HB}$ & $26,01 \mathrm{aB}$ & $26,49 \mathrm{aB}$ & 35,78 aA \\
\hline & $\mathrm{HC}$ & 20,15 abB & $23,73 \mathrm{aAB}$ & 28,86 aA \\
\hline \multirow{3}{*}{3,0} & HA & $12,56 \mathrm{bA}$ & $14,44 \mathrm{bA}$ & $19,85 \mathrm{bA}$ \\
\hline & $\mathrm{HB}$ & 26,64 aA & $20,75 \mathrm{abA}$ & $24,33 \mathrm{abA}$ \\
\hline & $\mathrm{HC}$ & 23,60 aA & 28,02 aA & 29,80 aA \\
\hline \multicolumn{2}{|c|}{ Média Geral } & \multicolumn{3}{|c|}{26,31} \\
\hline \multicolumn{2}{|l|}{$\mathrm{CV}(\%)$} & \multicolumn{3}{|c|}{16,51} \\
\hline
\end{tabular}

1/ HA: ametryn (2.000 $\left.\mathrm{g} \mathrm{ha}^{-1}\right)$; HB: trifloxysulfuron-sodium $\left(22,5 \mathrm{~g} \mathrm{ha}^{-1}\right)$; HC: ametryn + trifloxysulfuron-sodium $(1.673+$ $37,0 \mathrm{~g} \mathrm{ha}^{-1}$ ). ${ }^{2 /}$ Médias seguidas por mesmas letras minúsculas na coluna, dentro de cada genótipo entre os herbicidas e seguidas por mesmas letras maiúsculas, na linha, entre os genótipos não diferem entre si pelo teste de Tukey ( $\mathrm{p} \leq 0,05)$

genótipos de cana-de-açúcar refletiu na menor produção da MSPA da cultura. Nesse sentido, Ferreira et al. (2005), ao trabalharem com o ametryn + trifloxysulfuron-sodium aplicado sobre vários genótipos, constataram que há relação entre a maior intoxicação e a menor produção de massa da matéria seca da parte aérea. Avaliando ametryn, trifloxysulfuronsodium, ametryn + trifloxysulfuron-sodium e 2,4-D, Reis et al. (2008) relataram que ametryn + trifloxysulfuron-sodium foi o que menos afetou a produção de MSPA, para o genótipo RB867515.

Ferreira et al. (2005) verificaram para o genótipo RB855113 tendência de redução na altura de planta, na área foliar, no número de folhas e nas massas da matéria seca foliar e caulinar com o aumento da dose da mistura ametryn + trifloxysulfuron-sodium. Por outro lado, esses autores observaram também que para o RB867515 essa tendência de redução foi menor, sendo esse cultivar considerado pelos autores um dos mais tolerantes à mistura formulada, o que vem corroborar de maneira geral o encontrado neste trabalho.
Analisado em conjunto os resultados obtidos neste trabalho tanto nas comparações efetuadas por regressões quanto por testes de médias, conclui-se que existem diferenças entre os genótipos avaliados e que eles foram afetados de forma diferenciada pela aplicação de herbicidas e diferentes doses comerciais destes para as variáveis: intoxicação aos 14, 28 e 42 DAT, área foliar e massa da matéria seca da parte aérea das plantas de canade-açúcar avaliadas aos 80 dias após a brotação das gemas. Os genótipos SP80-1816 e RB855113 foram menos tolerantes aos herbicidas ametryn e trifloxysulfuronsodium e à mistura formulada de ametryn + trifloxysulfuron-sodium do que o RB867515 em todas as doses testadas, apresentando elevados índices de intoxicação aos 14, 28 e 42 dias após a aplicação dos tratamentos. O genótipo RB855113 foi o mais sensivel a todos os herbicidas e doses testados para as variáveis área foliar e massa da matéria seca da parte aérea, seguido do SP80-1816. O genótipo mais tolerante a todos os herbicidas foi o RB867515.

\section{LITERATURA CITADA}

ADATI, C.; OLIVEIRA, V. A.; KARAM, D. Análise matemática e biológica dos modelos de estimativa de perdas de rendimento na cultura devido à interferência de plantas daninhas. Planta Daninha, v. 24, n. 1, p. 1-12, 2006.

AZANIA, C. A. M. et al. Seletividade de imazapic às soqueiras de cana-de-açúcar (Saccharum spp.). Planta Daninha, v. 19, n. 3, p. 345-350, 2001

AZANIA, C. A. M. et al. Seletividade de herbicidas. II aplicação de herbicidas em pós-emergência inicial e tardia da cana-de-açúcar na época das chuvas. Planta Daninha, v. 23, n. 4, p. 669-675, 2005.

AZANIA, C. A. M. et al. Seletividade de herbicidas. III Aplicação de herbicidas em pós-emergência inicial e tardia da cana-de-açúcar na época da estiagem. Planta Daninha, v. 23, n. 3, p. 489-495, 2006.

BARELA, J. F.; CHRISTOFFOLETI, P. J. Seletividade de herbicidas aplicados em pré-emergência da cultura da cana-deaçúcar (RB867515) tratada com nematicidas.

Planta Daninha, v. 24, n. 2, p. 371-378, 2006.

COMISSÃO DE FERTILIDADE DO SOLO DO ESTADO DE MINAS GERAIS - CFSEMG. Recomendações para o uso de corretivos e fertilizantes em Minas Gerais - 5aㅗ aproximação. Viçosa, MG: Universidade Federal de Viçosa, 1999. $359 \mathrm{p}$. 
CHRISTOFFOLETI, P. J. et al. Carfentrazone-ethyl aplicado em pós-emergência para o controle de Ipomoea spp. e Commelina benghalensis na cultura da cana-de-açúcar. Planta Daninha, v. 24, n. 1, p. 83-90, 2006.

DAS, A. C.; DEBNATH, A.; MUKHERJEE, D. Effect of the herbicides oxadiazon and oxyfluorfen on phosphates solubilizing microorganisms and their persistence in rice fields. Chemosphere, v. 53, n. 3, p. 217-221, 2003.

EMPRESA BRASILEIRA DE PESQUISA AGROPECUÁRIA - EMBRAPA. Centro Nacional de Pesquisa Agropecuária de Solos. Sistema brasileiro de classificação de solos. Rio de Janeiro: 2006. 412 p.

FREITAS, S. P. et al. Controle químico de Rottboellia exaltata em cana-de-açúcar. Planta Daninha, v. 22, n. 3, p. 461-466, 2004.

FERREIRA, E. A. et al. Sensibilidade de cultivares de canade-açúcar à mistura trifloxysulfuron-sodium + ametryn. Planta Daninha, v. 23, n. 1, p. 93-99, 2005.

INMAN-BAMBER, N. G. Temperature and seasonal effects on canopy development and light interception of sugarcane.

Field Crops Res., v. 36, n. 1, p. 41-51, 1994.

KUVA, M. A. et al. Períodos de interferência das plantas daninhas na cultura da cana-de-açúcar. III - Capim-brachiaria (Brachiaria decumbens) e capim-colonião (Panicum maximum). Planta Daninha, v. 21, n. 1, p. 37-44, 2003.

NEGRISOLI, E. et al. Seletividade de herbicidas aplicados em pré-emergência na cultura da cana-de-açúcar tratada com nematicidas. Planta Daninha, v. 22, n. 4, p. 567-575, 2004.

OLIVEIRA, R. A. et al. Crescimento e desenvolvimento de três cultivares de cana-de-açúcar, em cana-planta, no Estado do Paraná. Sci. Agr., v. 5, n. 1-2, p. 87-94, 2004.
PROCÓPIO, S. O.; SILVA, A. A.; VARGAS, L. Manejo e controle de plantas daninhas em cana-de-açúcar. In: VARGAS, L.; ROMAN, E. S. (Ed.). Manual de manejo e controle de plantas daninhas. Bento Gonçalves: Embrapa Uva e Vinho, 2004. p. $397-452$.

REIS, M. R. et al. Dinâmica de nutrientes em tecidos foliares de cana-de-açúcar após aplicação de herbicidas. Planta

Daninha, v. 26, n. 1, p. 175-184, 2008.

RIZZARDI, M. A. et al. Ação de herbicidas sobre mecanismos de defesa das plantas aos patógenos. Ci. Rural, v. 33, n. 5 , p. $957-965,2003$.

RODRIGUES, B. N.; ALMEIDA, F. R. Guia de herbicidas. 5.ed. Londrina: Edição dos Autores, 2005. 591 p.

SYNGENTA, Syngenta Foundation. Disponível em: < http:// www.syngenta.com/products/services/krismat $>$. Acesso em: 30 nov. 2008

TERUEL, D. A.; BARBIERI, L. A.; FERRARO Jr., L. A. Sugarcane leaf area index modeling under different soil water conditions. Sci. Agr., v. 54, p. 39-44, 1997. Número Especial

VELINI, E. D. et al. Avaliação dos efeitos de doses do herbicida clomazone, aplicado em pós-emergência inicial, sobre o crescimento e produtividade de soqueira de cana-deaçúcar (Saccharum officinarum cv. SP71-1406). STAB, v. 12, n. 2 , p. $30-35,1993$.

VELINI, E. D. et al. Avaliação da seletividade da mistura de oxyfluorfen e ametryne, aplicada em pré e pós-emergência, a dez variedades de cana-de-açúcar (cana planta).

Planta Daninha, v. 18, n. 2, p. 123-134, 2000. 